\title{
Preliminary development of a reference conceptual framework about social responsibility of public hospitals in China
}

\author{
Lizheng Shi ${ }^{1}$, Fei Liang ${ }^{2}$, Hui Shao ${ }^{1}$, Xianzhi Hu${ }^{2}$, Qian $\mathrm{Gu}^{2}$, Wenbin $\mathrm{Liu}^{2}$, Xiong $\mathrm{Ke}^{2}$, Thomas Jefferson Stranova ${ }^{1}$, \\ Yingyao Chen*2,3,4 \\ ${ }^{1}$ School of Public Health and Tropical Medicine, Tulane University, New Orleans, USA \\ ${ }^{2}$ School of Public Health, Fudan University, Shanghai, China \\ ${ }^{3}$ Key Lab of Health Technology Assessment (Ministry of Health), Fudan University, Shanghai, China \\ ${ }^{4}$ Collaborative Innovation Center of Social Risks Governance in Health, Shanghai, China
}

Received: October 28, 2014

DOI: $10.5430 /$ jha.v4n2p23
Accepted: December 28, 2014 Online Published: January 29, 2015

URL: http://dx.doi.org/10.5430/jha.v4n2p23

\begin{abstract}
Public hospitals play an integral part in the health, welfare, and success of the communities they serve. In their roles, public hospitals are expected to embrace the principles of social responsibilities, but these ideas are often vaguely or poorly defined or implemented in the healthcare setting. This paper uses China as a case study to develop a theoretical framework of social responsibilities for public hospitals that can be applied to evaluate hospital performance on social responsibility and to enhance health management educational programs. A systematic literature review and Delphi panel of Chinese domestic scholars were used to examine potential indicators to measure social responsibilities of public hospitals. A four-level of corporate social responsibilities (CSR) framework was combined with four performance parameters for medical institutions (accessibility, appropriateness, quality, and efficiency) to create a matrix structure of social responsibilities with empirically studied indicators.
\end{abstract}

Key Words: Public hospital, Health management, Social responsibilities, Health ethics

\section{Introduction}

The studies on institutional social responsibilities have been reported in the literature since the 1950s. In 1953, Howard R. Bowen ${ }^{[1]}$ published his landmark book Social Responsibilities of the Businessman which many argue marks the beginning of the modern period of literature on corporate social responsibilities (CSR). He promulgated that actions of the largest business companies touched the lives of citizens at many points. Thus he proposed his definition as decisions and policies that should be in accordance with the desirable values and objectives of society. At that time $93.5 \%$ of businessmen agreed with this point. ${ }^{[2]}$ In the 1960s, Keith Davis ${ }^{[3]}$ was the most influential scholar on this topic. He proposed the "Iron Law of Responsibilities", indicating that social responsibilities of organizations should be commensurate with companies' social power. He also claimed that avoiding social responsibilities would lead to gradual erosion of social power. McGuire, ${ }^{[4]}$ another influential scholar at that time, expanded the concept of CSR into business ethics and cooperate citizenship. Other scholars also weighed in on the concept, for instance, Clarence C. Walton ${ }^{[5]}$ proposed that the essential factor of which constitutes social responsibility was a degree of voluntarism. Harold

*Correspondence: Yingyao Chen; Email: yychen@ @hmu.edu.cn; Address: School of Public Health, Fudan University, Shanghai, China. 
Johnson $^{[6]}$ pointed out four perspectives of CSR including conventional wisdom, long-run profit maximization, utility maximization, and lexicographic view. Carroll ${ }^{[7]}$ set forth the four-part conceptualization of CSR with the idea of combining economic, legal, ethical, and philanthropic characteristics together into a single model.

Hospitals, including public hospitals, while they have large amount of differences on mission, responsibilities, functions, quality and financing from general companies, are still economic units essentially. ${ }^{[8]}$ Therefore, this four-part framework of CSR can be adapted into a social responsibilities framework for hospitals as follows:

(1) In the traditional CSR model, economic responsibilities are those characteristics which companies have as economic units. Companies produce goods to the society members and gain their profits back in return. The profit motive was established as their primary incentive. ${ }^{[9]}$ Specifically for medical institutions or hospitals funded both by government investment and operational profit, hospitals cannot function without good economic efficiency, therefore gaining surplus or profit is an essential part for routine work. However, they should not make surplus or profit maximization as their primary goal, instead improve population health. Achieving good economic responsibilities is the foundation for hospitals' public welfare of health promotion.

(2) Legal responsibilities are those characteristics which the society put onto cooperation by laws and regulations. Legal responsibilities and economic responsibilities are the fundamental elements of CSR system. Medical institutions must follow all the related laws, regulations, policies and guidelines issued by the governments. In addition, all their services' levels and skills should meet the required quality standards.

(3) Ethical responsibilities, although some of which about fairness and social justice have already embodied into laws, are still far beyond the law restrictions. For most of time, ethical responsibilities were seen as those values and norms which contain a higher requirement of performance beyond legal restrictions. It is hard to define what exactly the rules are and to what level of the ethical responsibilities is. Therefore, currently ethical responsibilities are those organizations which perform in consistency with the societies' expectations. Similarly, medical institutions should have good knowledge of moral requirement of the society. All the services, products, treatments, medicines, and physical examinations should be appropriate, cost-effective, or patient-oriented. Social outcomes to meet good ethical standards should be one of the important goals for medical institutions.

(4) Philanthropic responsibilities are those which require companies to participate in the activities for promot- ing human welfare. The main difference between philanthropic and ethical responsibilities is of voluntary nature. For most of time, even a company does not fulfill its philanthropic responsibilities, the society usually does not blame it. As for philanthropic responsibilities, medical institutions should provide additional medical services for vulnerable populations. These services could not be covered by the medical assistance program or medical insurance program, and they are treated as uncompensated care by medical institutions. Instead those medical institutions provide them voluntarily. Medical institutions should implement humanitarian policies such as fee reduction and free services for the special populations.

China has started a new round of health reform since 2009 with its overall goal of establishing an essential healthcare service system to which everyone can have access. This health reform was consisted with five essential objectives, one of which is to reform public hospitals. Many indicators including the social responsibilities of public medical institutions were proposed to measure the outcomes of the reform in public medical institutions. Indeed, improving social responsibilities of medical institutions is one of the policy goals for governments, society, and even medical institutions themselves. And it is acknowledged that there is a lack of awareness of responsibilities in many organizations. ${ }^{[10]}$ Since public medical institutions are mainly depending on use fees services and only have less than 10 percent subsidies from the government to their operating budget, their behaviors are driven by economic incentives, which are often in conflict with the interests of the general public. While many medical innovations which intend to support or promote the social responsibilities of medical institution, especially those with their mission to promote public welfare, there is still a lack of clear framework to define and evaluate the social responsibilities after the idea of corporate social responsibilities was put forward and debated for about half of a century. ${ }^{[11]}$ In the context of China's health reform, we examined a theoretical framework for measuring the social responsibilities to specify the processes to define social responsibilities and their indicators.

\section{Methods}

Chinese Biomedical Literature Database and Wanfang Database were searched using the search terms of "hospital" or "medical institutions" or "welfare" or "responsibility". A total of 1,216 papers were found between 2003 and 2012. The initial screening on the articles suggested that different scholars have varieties of viewpoints on social responsibilities. We selected four essential parameters for evaluation of the social responsibilities: accessibility, appropriateness, quality and efficiency.

An initial list of indicators including seven potential first- 
degree indicators and 29 potential second-degree indicators was collected through a systematic review on the 1,216 papers mentioned above. The screening process for original indicators was put forward under four basic principles: (1) this process should be comprehensive so that any indicators might be related to medical responsibilities should be taken into consideration; (2) the indicators should be representative for the institutions current situation and hard to be affected by external factors; (3) the indicators should be able to be evaluated continuously; and (4) data for the indicators should be accessible.

The Delphi method ${ }^{[12]}$ was adopted to screen and decide the indicators for evaluating the social responsibilities for medical institution. The Delphi panel consisted of 40 experts from universities or research institutions, government agencies/departments, and medical institutions. They all met the following pre-defined criteria: relevant knowledge and experience, capacity, willingness and sufficient time to participate in the Delphi panel.
Correspondences were made through emails. For round 1, we provided the initial list along with a self-evaluation form to all the experts of the panel, 31 members responded to the questionnaire $(77.5 \%)$. A round 2 communication was conducted after we had revised and added 11 new indicators to the list by analyzing the data from round 1. A total of 28 experts responded to the revised questionnaire (90.3\%).

\section{Results}

\subsection{Theoretical framework for social responsibilities of medical institutions}

A systematic review on the 1,216 papers had led to an appreciation of different opinions toward social responsibilities among the national scholars in China after we screened different perspectives. ${ }^{[8,13-27]}$ Despite the differences, their focuses of indicators were comparatively converged in to the main themes as follows (see Table 1).

Table 1: Indicators of social responsibilities based on systematic review

\begin{tabular}{|c|c|c|c|c|c|}
\hline Studies & Accessibility & Appropriaten & Quality & Efficiency & Others \\
\hline Ling, Li & $\bullet$ & & & $\bullet$ & Policy Function \\
\hline Shaodong, Li & $\bullet$ & & & & Social duty, ethic \\
\hline Junhua, Wang & $\bullet$ & & & & Public education. Public character \\
\hline Yaguang, Chen & $\bullet$ & & & & Public health emergency. Aid to weak. \\
\hline Junfeng, Zhang & $\bullet$ & $\bullet$ & & & \\
\hline Ming, Zhao & $\bullet$ & - & $\bullet$ & $\bullet$ & \\
\hline Tao, Dai & $\bullet$ & & & & \\
\hline Bing, Leng & $\bullet$ & $\bullet$ & $\bullet$ & $\bullet$ & \\
\hline Yingyao, Chen & $\bullet$ & • & $\bullet$ & $\bullet$ & \\
\hline Lijuan, Pan & $\bullet$ & & & & \\
\hline Jixia, Xiong & $\bullet$ & & $\bullet$ & $\bullet$ & \\
\hline Xiaohe, Wang & $\bullet$ & - & $\bullet$ & $\bullet$ & \\
\hline Liang, Zhao & $\bullet$ & & $\bullet$ & $\bullet$ & \\
\hline Wengming, & $\bullet$ & & & $\bullet$ & \\
\hline Daxi, Zheng & $\bullet$ & - & $\bullet$ & $\bullet$ & \\
\hline Wenying, Xu & $\bullet$ & - & $\bullet$ & $\bullet$ & \\
\hline
\end{tabular}

We summarized four dimensions of social responsibility for health care: accessibility, appropriateness, quality, and efficiency. Specifically, accessibility is the requirement for which the medical institutions should provide accessible and fair medical services for all people in the community. The services should cover basic medical care and meet the needs of basic medical treatments for community members. Accessibility is the fundamental factors for medical institution responsibility and the essential tool to achieve universal assesses to basic health care.

Appropriateness means the services which medical institu- tions produced must fit health conditions and needs of patients. Physicians should not chase economic profits, but rather health or social outcomes. As the essential part of socio-conscious medical care system, medical institutions deliver basic health services which are likely appropriate for population health. ${ }^{[28]}$

The third element is quality. All technical skills and service quality need to meet the government standards and be continuously maintained. Quality in health care is very complex and needs to be defined in the framework of social responsibilities. 
The last one is efficiency, which includes macro-level efficiency and micro-level efficiency. For the former one, health system which consists of many medical institutions should contain medical expenses while maximize medical input as a whole. The improved cost efficiency should at last lead to achieving social outcomes. At micro- level, each medical institution should also take individual functional efficiency as its own responsibilities.

The four-level CSR structure was integrated into the fourparameter structure of medical institution performance from the systematic review. The theoretical framework for social responsibilities of medical institutions is presented (see Figure 1).

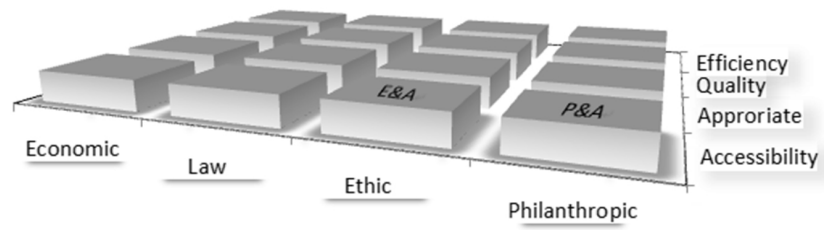

Figure 1: Theoretical framework of social responsibilities of medial institutions

It is acknowledged that social responsibility is a multidimensional concept which contains a large amount of elements and is required to be evaluated from many viewpoints by large number of stakeholders. ${ }^{[29]}$ Therefore, this theoretical framework would contribute to screening indicators for evaluating medical institutions social responsibilities in matrixes. This refinement process of indicators provided some insights of higher concentration level and more clear orientation to study social responsibilities.

\subsection{Screening indicators by Delphi method}

Through two rounds of Delphi interviews, we selected 28 key indicators within the theoretical framework (see Table 2). Indicators for "Accessibility" dimension included "ratio of health workers who provided medical care in a public health emergency in person month", "ratio of uncompensated public health emergency services", "ratio of health workers providing medical aid to farmers in person month", "ratio of health workers providing medical care to community in person month", "ratio of health workers providing aid to border areas in person month", "ratio of health workers providing foreign medical aid in person month", "ratio of health workers engaged in continue medical education in person month", "average time for each health worker organizing community health promotion per year", and "average number of free clinic per year".

Indicators of "Appropriateness" dimension included "crosssubsidization index", "ratio of essential drug revenue to total drug revenue", "outpatient (including emergency department) revenue per visit", "ratio of pharmaceutical revenue to total outpatient (including emergency department) revenue per visit", "inpatient revenue per admission", "ratio of pharmaceutical revenue to total inpatient revenue per admission", "ratio of VIP revenue to total revenue per year", "annual growth rate of outpatient (including emergency department) revenue per visit", and "annual growth rate of inpatient revenue per admission".

Indicators of "quality" dimension included "annul evaluation rating for quality control", "number of violations of quality standards", "patient-rated social responsibility score" and "patient-rated satisfaction score".

Last indicators dimension was "efficiency", which included "number of outpatient (including emergency) service for each physician per year", "number of inpatient service for each physician per year", "average length of stay", "annual balance rate" and "utility cost per RMB 10,000 yuan revenue".

\section{Discussion and conclusion}

Table 2 provides a general framework for social responsibilities of public hospitals, indicators are filled in different box which represents a module of the social responsibility system. This study has demonstrated a practical process of elucidating social responsibilities. In the future, other scholars may apply this process to social responsibilities in their own research settings and practice environments.

Using the current responsibility evaluation framework, indicators for some modules have already been well developed while others still remain blank or small sized. More indicators needed to be located into categories such as "Economic \& Quality", "Law \& Efficiency", "Ethic \& Efficiency" and "Philanthropic \& Efficiency". This framework produces enlightenment that it is highly efficient for researchers to develop either a single specific module, or more focused indicators within each category. It still takes a lot of work to fully complete this indicator matrix or modify the $4 \times 4$ matrix. It is important to put it into practice to improve social responsibilities in public health institutions. Since this framework from this study is more like a guideline for medical institutions to learn and create their own management system, this would be an opportunity for medical institutions to adapt this proposed standard framework into their own environments. Furthermore, this study makes advance in specifying a theoretical framework which enables people to get a systematic understanding for social responsibilities and complete the evaluation process through a comparatively rational and targeted way.

Besides the indicators screened in this study, we have found other essential indicators in the literature. Many international scholars suggest that uncompensated health care, like charity health care and bad debts, is the main factor reflecting philanthropic characteristics. ${ }^{[30]}$ Some other indicators 
such as "free health care for people without health insurance, the poor and the older people", "promote non-profit or low profit health service", "medical education", "medical research" could all be integrated into our theoretical framework. This study gives a possible method for other researchers who intended to study indicators for medical institutions' responsibilities in different environments. Additionally, this method provides governments a basis to develop efficient tools to examine and improve social responsibility in public medical institutions.

Table 2: Indicators for evaluating medical institutions responsibilities

\begin{tabular}{|c|c|c|c|c|}
\hline & Accessibility & Appropriateness & Quality & Efficiency \\
\hline Economic & $\%$ of reduction of service fee & $\begin{array}{l}\text { Outpatient (including emergency } \\
\text { department) revenue per visit, } \\
\text { Inpatient revenue per admission }\end{array}$ & & $\begin{array}{l}\text { Number of outpatient } \\
\text { (emergency department) } \\
\text { service for each physician } \\
\text { per year, Number of } \\
\text { inpatient service for each } \\
\text { physician per year, Average } \\
\text { length of stay, Annual } \\
\text { balance rate, Utility cost per } \\
\text { RMB 10,000 yuan revenue }\end{array}$ \\
\hline Law & $\begin{array}{l}\text { Number of health worker who } \\
\text { provided medical care in a public } \\
\text { health emergency in person month, } \\
\text { Ratio of health worker providing } \\
\text { medical aid to farmers in person } \\
\text { month, Ratio of health worker } \\
\text { providing medical aid to community in } \\
\text { person month, Ratio of health worker } \\
\text { providing aid to border areas in person } \\
\text { month, Ratio of health worker } \\
\text { providing foreign medical aid in } \\
\text { person month, Ratio of health worker } \\
\text { engaged in continue medical education } \\
\text { in person month }\end{array}$ & $\begin{array}{l}\text { Ratio of VIP services revenue to } \\
\text { total annual revenue }\end{array}$ & $\begin{array}{l}\text { Annual } \\
\text { evaluation rating } \\
\text { for quality } \\
\text { control, Number } \\
\text { of violations of } \\
\text { quality standards }\end{array}$ & \\
\hline Ethic & $\begin{array}{l}\text { Ratio for uncompensated public health } \\
\text { emergency services }\end{array}$ & $\begin{array}{l}\text { Cross-subsidization index, Ratio of } \\
\text { essential drug revenue to total drug } \\
\text { revenue, Ratio of pharmaceutical } \\
\text { revenue to total outpatient revenue } \\
\text { per visit, Ratio of pharmaceutical } \\
\text { revenue to total inpatient revenue } \\
\text { per admission, Annual growth rate } \\
\text { of outpatient revenue per visit, } \\
\text { Annual growth rate of inpatient } \\
\text { revenue per admission }\end{array}$ & $\begin{array}{l}\text { Patient-rated } \\
\text { satisfaction } \\
\text { score }\end{array}$ & \\
\hline Philanthropic & $\begin{array}{l}\text { Average time for each health worker } \\
\text { providing community health } \\
\text { promotion per month, Average } \\
\text { number of free clinic per year }\end{array}$ & & $\begin{array}{l}\text { Patient-rated } \\
\text { social } \\
\text { responsibility } \\
\text { score }\end{array}$ & \\
\hline
\end{tabular}

Our theoretical framework also plays a role in health management education. Managers in public medical institutions in China have been motivated to increase their institutions' surplus/profits and their own compensation and bonuses. Despite the supposedly non-for-profit mission for medical institutions in China, managers are now facing complex challenges: managing the delivery of hospital services with very little government funding on operation costs. This is occurring while the demand on social responsibility dimension rises. For example, public opinion is pushing the public medical institutions to change its function from treating disease into health strengthening and prevention. Thus, a full awareness of social responsibility is becoming highly required for medical institution leaders, for instance, under the new health reform in China. This new social responsibility competency for managers requires adding a new education activities related to social responsibilities. Our theoretical framework for medical institution's social responsibility provides an appropriate outline for health management training and education. ${ }^{[31]}$ It is highly recommended that this framework should be integrated into MPH, MHA or even bachelor in health management's education program 
in China. Since some components of social responsibilities also consider charity and philanthropic attributes, this study may also contribute to a broader awareness about social responsibilities for health managers for other settings and countries.

\section{Limitations}

This study has its limitations. Due to a lack of standard procedures, screened indicators to the framework are based on personal experience of researchers and the expert panel. Because of the limitation of individual's experience of populating indicators into the framework, Table 2 can be viewed as an approximation rather than a standard model. In a followup study, researchers should screen indicators by using an internal consistency measure for a single module.

Another limitation for this study is the vague boundary between modules. Overlapping areas between modules could be found, and future scholars who will use this framework may encounter problems related to this misconception. This could lead to duplicate screening and difficult data collection. A more specific study with pilot use of the evaluative tool will be needed to improve discriminant validity of dif- ferent modules.

In summary, a framework of social responsibilities of public medical institutions have been proposed by integrating four-level of CSR theory and medical institutions' fourparameter performance structure. This framework will be populated with empirically derived indicators in the case study in China by the study team. Despite of caution on generalizability of this framework, social responsibilities of medical institutions can play a role in health education and evaluation studies on performance of medical institutions and improvement in population health outcomes.

\section{Conflicts of Interest Disclosure}

The authors declare that they have no competing interests.

\section{Acknowledgements}

We gratefully acknowledge the funding support of the National Natural Science Foundation of China (70973025). Fudan Overseas Visiting Scholar Program supported Dr Shi traveling to Fudan to discuss research and write paper with Fudan research team.

\section{References}

[1] Bowen, H. R. Social responsibilities of the businessman. New York: Harper \& Row. 1953.

[2] Carroll, A.B. Three-Dimensional Conceptual Model of Corporate Social Performance, Academy of Management Review. Academy of Management Review. 1979; 4: 497-505.

[3] Davis, K. Can business afford to ignore social responsibilities? California Management Review. 1960; 2: 70-76. http://dx.doi .org /10.2307/41166246

[4] McGuire, J. Business and society. New York: McGraw-Hill. 1963.

[5] Walton, C. Corporate social responsibilities. Belmont, CA: Wadsworth. 1967.

[6] Johnson, H. Business in contemporary society: Framework and issues. Belmont, CA: Wadsworth. 1971.

[7] Carroll, A. B. The Pyramid of Corporate Social Responsibility: Toward the Moral Management of Organizational Stakeholders. Business Horizons. 1991.

[8] Chen, Y., Li, C.L., E, Q., Tian, D., Han, P. Policy suggestions for improving public walfare of public medical institutions. CHINESE JOURNAL OF HOSPITAL ADMINISTRATION. 2007; 23: 649651.

[9] Paul, C.G., Nile, W.H., Jared, M.H. Toward a General Theory of CSRs: The Roles of Beneficence, Profitability, Insurance, and Industry Heterogeneity. Business Society. 2010; 49: 316-347. http: //dx.doi.org/10.1177/0007650308315494

[10] Liang, W. Health service management. Beijing: The People's Medical Publishing House. 2003.

[11] Yang, F. Enlightenment on Public-founded Hospitals from Medical institutions aboard. CHINESE JOURNAL OF HOSPITAL ADMINISTRATION. 2008; 24 (10): 664-665.

[12] Zeng, G. Modern epidemiology: methods and Applications. Beijing: Beijing Medical University and China Xie-he Medical University Joint Publishing House. 1993.
[13] Chen, Y. Social Responsibilities of Public-founded Medical Institutions. Health Policy. 2006; (10): 59-60.

[14] Dai,T., Tian, X., You, C. Theoretical basis and governmental responsibilities for establishing public hospitals in China. CHINESE JOURNAL OF HEALTH POLICY. 2009; 2(8): 7-13.

[15] Leng, B., Liu, Z. Discussion on Social Responsibilities in Medical Institutions. CONTEMPORARY MEDICINE. 2009; 15(31): 12-13.

[16] Li, S. Inspiration from Emergent Hazards - Discussion on Several Issues Paid Attention to in Hospital Management. CHINESE HEALTH SERVICE MANAGEMENT. 2004; 20(1): 22-23.

[17] Li, L., Chen, Q., Zhang, W., et al. The public-interest nature of the public hospitals and its support system. Chinese Journal of Health Policy. 2010 5; 3(5): 7-10.

[18] Pan, L. Hospital Welfare Service Marketing. Chinese health elites. 2009; (7): 68-69.

[19] Wang, J. Social Responsibilities needed to be strengthened in medical institutions. Chinese Journal of Hospital Administration. 2005; 21(3): 205-207.

[20] Wang, X. Consideration on Constructing Social Evaluation System of Public Hospital in New Period. Chinese Hospital Management. 2006; 26(4): 5-7.

[21] Xia, W., Zhang, X., Tian, W. Review and analysis of focused problems of public hospital reform in China. CHINESE HEALTH RESOURCES. 2011; 14(2): 72-73.

[22] Xiong, J., Xu, A. Suggestion on Reform of State-Owned Hospitals' Governance Structure Based on Its Commonweal Character. Chinese Health Service Management. 2010; 11: 747-748.

[23] Xu, W. Suggestions on Strenghen Welfare of Public-founded Hospitals. CHINESE RURAL HEALTH SERVICE ADMINISTRATION. 2010; 4: 282-284.

[24] Zhang, J., Liu, Y., Dan, X. Analysis of Necessity and Feasibility of Establishing Public Welfare Hospital. CHINESE HEALTH SERVICE MANAGEMENT. 2007; 23(10): 669-671. 
[25] Zhao, L., J, X., Chen, Z. Financial Compensation Mechanism and Public Welfare for Medical Reform. CHINESE JOURNAL OF HOSPITAL ADMINISTRATION. 2009; 10: 666-668.

[26] Zhao, M., Ma, J. Research on evaluation system and impact factors for public interest nature in public hospitals. JOURNAL OF SHANGHAI JIAOTONG UNIVERSITY(MEDICAL SCIENCE). 2009; 29(6): 737-740.

[27] Zheng, D. The Path Selection for the Public Hospital Returning to Public Welfare in the Background of New Medical Reform. MOD ERN HOSPITAL MANAGEMENT. 2010; 5: 26-29.

[28] Han, S. Understanding and Idea about Public Welfare of Publicfounded Hospitals. CHINESE HOSPITAL MANAGEMENT. 2008;
28(5): 2-3.

[29] Cheng, W., Long, X., Fan, D. Research on Establishment of Public Hospital Comprehensive Performance Evaluation Index System. CHINESE HEALTH ECONOMICS. 2010; 29(9): 68-70.

[30] Trost, S. Crowding Out in Corporate Charitable Giving. Virginia: Virginia Tech. 2008.

[31] Onwujekwe O., Onoka C, Uguru N, Tasie N, Uzochukwu B, Kirigia $\mathrm{J}$, et al. Socio-economic and geographic differences in acceptability of community-based health insurance. Public Health. 125(2011): 806-808. PMid: 22036685. http://dx.doi.org/10.1016/j.p uhe. 2011.09 .006 